\section{Commentary: Through the looking glass: Is the consolidation/tumor ratio more important than size for clinical T1N0 lung cancer with a dominant ground-glass opacity?}

Jules Lin, MD

In this issue of the Journal, Ito and colleagues ${ }^{1}$ report excellent 10-year survival in patients from the Japanese Clinical Oncology group (JCOG) 0201 study with clinical T1N0 lung adenocarcinoma with a tumor size $\leq 3 \mathrm{~cm}$ and a dominant ground-glass opacity with a consolidation/tumor ratio $(\mathrm{CTR}) \leq 0.5$ and suggest that these patients are potential candidates for sublobar resection. Nodules with a groundglass component are less invasive than pure solid lung cancers, and the prognosis was substantially better in group A $(\mathrm{CTR}<0.25)$ than group $\mathrm{C}(\mathrm{CTR}>0.5)$ in the current study.

The results are interesting and show that for T1 tumors, the CTR may be as important as the tumor size alone in terms of long-term survival. In contrast, the American Joint Committee on Cancer 8th edition staging system is based on size alone. ${ }^{2}$ For part-solid nodules, it may be better to focus on the size of the solid component rather than the entire lesion, and the size of the solid, invasive component may be more highly associated with survival. ${ }^{3}$ However, Hattori and colleagues ${ }^{4}$ found that neither the maximum tumor size nor the solid component size was prognostic in part-solid lung cancers and propose that pure ground-glass and part-solid nodules be classified as Tis and T1a independent of their size. In the current study, the mean CTR in group A was 0, consistent with pure ground-glass lesions. Although the histopathologic definition had not yet been adopted during the study period, only 1 of 35 $(2.9 \%)$ were invasive cancers, and the remainder were most likely adenocarcinoma-in-situ. We are no longer

\footnotetext{
From the Department of Surgery, Section of Thoracic Surgery, University of Michigan Medical Center, Ann Arbor, Mich.

Disclosures: Author has nothing to disclose with regard to commercial support.

Received for publication Dec 21, 2019; accepted for publication Dec 22, 2019; available ahead of print Jan 11, 2020.

Address for reprints: Jules Lin, MD, Section of Thoracic Surgery, 1500 E Medical Center Dr, 2120TC/5344, Ann Arbor, MI 48109-5344 (E-mail: juleslin@umich. edu).

J Thorac Cardiovasc Surg 2021;161:291-2

0022-5223/\$36.00

Copyright (c) 2020 by The American Association for Thoracic Surgery

https://doi.org/10.1016/j.jtcvs.2019.12.081
}

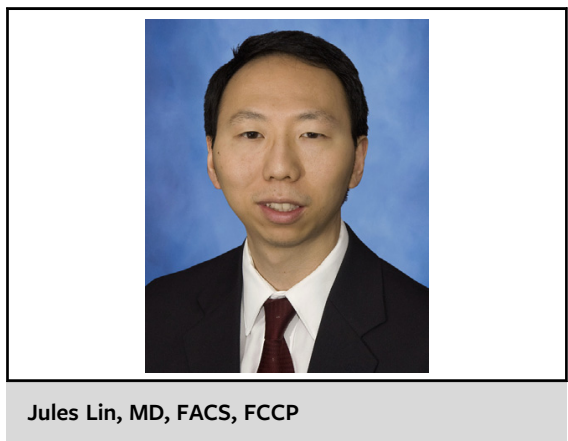

\begin{abstract}
CENTRAL MESSAGE
As we await results of randomized trials on sublobar resection, the consolidation/tumor ratio may need to be considered in determining treatment for T1No nodules with a dominant ground-glass opacity.
\end{abstract}

resecting small, pure ground-glass lesions, often waiting until a solid, invasive component develops, and it is unclear whether the majority of these group A lesions would be resected currently.

The study was based on clinical staging. Although there were no patients in group A or B with positive level 11 or 12 lymph nodes, in groups $\mathrm{C}$ and $\mathrm{D}$, the frequency of $\mathrm{pN} 1$ disease was $3.6 \%$ and $8.5 \%$, respectively, highlighting the importance of adequate nodal staging and intraoperative frozen section during segmentectomy to confirm that a lobectomy is not necessary. The difference in survival between groups $\mathrm{A} / \mathrm{B}$ and $\mathrm{C} / \mathrm{D}$ would likely be less if pathologic staging was used and only $\mathrm{pN} 0$ patients included.

We currently await the final results from phase 3, randomized trials evaluating sublobar resection versus lobectomy for stage IA lung cancer. The Cancer and Leukemia group B (CALGB) 140503 trial is focused on tumors $\leq 2 \mathrm{~cm}^{5}$ Pure ground-glass nodules were excluded, but consolidation size was not taken into account. The JCOG0802 trial is evaluating segmentectomy versus lobectomy for tumors $\leq 2 \mathrm{~cm}$ with a CTR $>0.5 .{ }^{6}$ It will be important to consider the relative importance of CTR to determine how these results should be applied to part-solid nodules and whether we should follow Alice and Ito and colleagues through the looking glass and into the wonderland of sublobar resection for lung cancers $\leq 3 \mathrm{~cm}$ with a dominant ground-glass opacity. 


\section{References}

1. Ito H, Suzuki K, Mizutani T, Aokage K, Wakabayash M, Fukuda H, et al; Japan Clinical Oncology Group Lung Cancer Surgical Study Group. Long-term survival outcome after lobectomy in patients with clinical T1N0 lung cancer: a 10-year follow-up of JCOG0201. J Thorac Cardiovasc Surg. 2021;161:281-90.

2. Goldstraw P, Chansky K, Crowley J, Rami-Porta R, Asamura H, Eberhardt WE, et al; International Association for the Study of Lung Cancer Staging and Prognostic Factors Committee, Advisory Boards, and Participating Institutions; International Association for the Study of Lung Cancer Staging and Prognostic Factors Committee Advisory Boards and Participating Institutions. The IASLC Lung Cancer Staging Project: Proposals for Revision of the TNM Stage groupings in the Forthcoming (Eighth) Edition of the TNM Classification for Lung Cancer. J Thorac Oncol. 2016;11:39-51.

3. Maeyashiki T, Suzuki K, Hattori A, Matsunaga T, Takamochi K, Oh S. The size of consolidation on thin-section computed tomography is a better predictor of survival than the maximum tumour dimension in resectable lung cancer. Eur $J$ Cardiothorac Surg. 2013;43:915-8.

4. Hattori A, Matsunaga T, Takamochi K, Oh S, Suzuki K. Neither maximum tumor size nor solid component size is prognostic in part-solid lung cancer: impact of tumor size should be applied exclusively to solid lung cancer. Ann Thorac Surg. 2016;102:407-15.

5. Altorki NK, Wang X, Wigle D, Gu L, Darling G, Ashrafi AS, et al. Perioperative mortality and morbidity after sublobar versus lobar resection for early-stage non-small-cell lung cancer: post-hoc analysis of an international, randomised, phase 3 trial (CALGB/Alliance 140503). Lancet Respir Med. 2018; 6:915-24.

6. Nakamura K, Saji H, Nakajima R, Okada M, Asamura H, Shibata T, et al. A phase III randomized trial of lobectomy versus limited resection for small-sized peripheral non-small cell lung cancer (JCOG0802/WJOG4607L). Jpn J Clin Oncol. 2010;40:271-4.
See Article page 281.

\section{Commentary: Is segmentectomy ready to be accepted as the standard of care?}

\author{
Wentao Fang, MD
}

Lung cancers are increasingly detected at earlier stages with computed tomographic screening, especially those lesions containing ground glass opacities. In the article in this issue of the Journal by Ito and colleagues ${ }^{1}$ for the Japan Clinical Oncology Group (JCOG), excellent survival and few recurrences were found for lung cancers containing ground glass opacities. It is thus reasonable to think of limited resections as an alternative to lobectomy for such small, indolent lesions.

Two things need to be verified before sublobar resections can be accepted as standard of care. The first is their oncologic noninferiority to lobectomy. The JCOG 0201 study heralded a series of beautifully designed imaging-guided trials focusing on sublobar resections, including JCOG 0804 (big wedge resection for tumors of size $\leq 2 \mathrm{~cm}$ and consolidation/tumor ratio $[\mathrm{CTR}] \leq 0.25),{ }^{2}$ JCOG 1211

From the Department of Thoracic Surgery, Shanghai Chest Hospital, Jiaotong University Medical School, Shanghai, China.

Disclosures: Author has nothing to disclose with regard to commercial support.

Received for publication Jan 8, 2020; revisions received Jan 8, 2020; accepted for publication Jan 13, 2020; available ahead of print Jan 31, 2020.

Address for reprints: Wentao Fang, MD, Department of Thoracic Surgery, Shanghai Chest Hospital, 241 Huaihai Rd W, Shanghai 200030, China (E-mail: vwtfang@ hotmail.com).

J Thorac Cardiovasc Surg 2021;161:292-3

$0022-5223 / \$ 36.00$

Copyright (c) 2020 by The American Association for Thoracic Surgery

https://doi.org/10.1016/j.jtcvs.2020.01.037
Check for updates

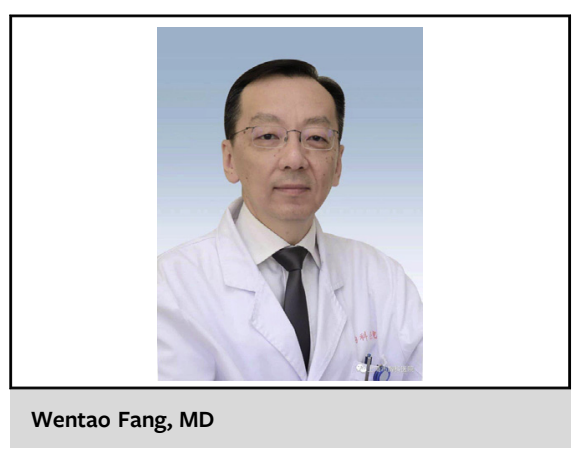

CENTRAL MESSAGE

Even though the results of 2 ongoing trials are expected, it is still too early to consider segmentectomy as the standard of care for early stage lung cancers.

(segmentectomy for tumors of size $\leq 3 \mathrm{~cm}$ and CTR $\leq 0.5$ ), ${ }^{3}$ and JCOG 0802 (segmentectomy vs lobectomy for tumors of size $\leq 2 \mathrm{~cm}$ and CTR $>0.5) .{ }^{4}$ It is well known, however, that solid components on computed tomographic scans do not always correspond to invasive histologic type. Furthermore, many lesions containing ground glass opacities are heterogeneous in density or have multifocal solid components, making accurate measurement difficult. It would be interesting to see how the JCOG 0802 results coincide with the CALGB 140503 study, ${ }^{5}$ which also compares segmentectomy versus lobectomy but is based on total tumor size only. 